Published in final edited form as:

Methods Mol Biol. 2015 ; 1214: 225-242. doi:10.1007/978-1-4939-1462-3_14.

\title{
Avians as a Model System of Vascular Development
}

\author{
Michael Bressan and Takashi Mikawa \\ Cardiovascular Research Institute, University of California San Francisco, 555 Mission Bay Blvd \\ South, MC3120, San Francisco, CA 94143-3120
}

\section{Summary}

\begin{abstract}
For more then 2000 years philosophers and scientists have turned to the avian embryo with questions of how life begins (Aristotle; Needham, 1959). Then, as now, the unique accessibility of the embryo both in terms of acquisition of eggs from domesticated fowl, and ease at which the embryo can be visualized by simply opening the shell, have made avians an appealing and powerful model system for the study of development. Thus, as the field of embryology has evolved through observational, comparative, and experimental embryology, into its current iteration as the cellular and molecular biology of development, avians have remained a useful and practical system of study.
\end{abstract}

\section{Keywords}

Vascular Development; Avian Embryos; Chick/Quail Chimera; Somatic Transgenesis; Cell Fate Tracing

\section{Introduction}

Specifically in regards to vascular development, avians have enjoyed a particular degree of popularity. This has been, in part, due to the high level of conservation in vascular patterning present within amniotes, including avians and mammals, coupled with the ease at which embryonic vascularization can be directly viewed in an open egg. As such, much of our fundamental understanding regarding the embryonic origins of blood, endothelium, and cardiac muscle derive directly from studies preformed in birds (Coffin and Poole, 1988; Noden, 1989; Pardanaud et al., 1989; Pardanaud et al., 1996; Rawles, 1943; Stalsberg and DeHaan, 1969). Modern advances including the creation of the annotated chick genome (Wallis et al., 2004), gene expression profiling, live imaging, improved somatic transgenesis, and gene specific attenuation of RNA levels, have also greatly added to the classical strengths of the avian embryo. In this chapter basic avian embryonic manipulation will be discussed with particular attention placed on in vivo experimental techniques that have proven useful for the study of vascular development.

The two most prominent avian species currently used to study development are the domestic chicken (Gallus gallus) and the Japanese quail (Cortonix japonicum). Eggs from both organisms can be acquired year round from local farms and can be stored cold (typically 
12-16 C) for up to 7 days before use. These eggs can then be transferred to a humidified incubator at $38 \mathrm{C}$ and developed to a desired stage. Of particular utility for the field of cardiovascular development, the avian embryo develops as a flattened disk which floats on the surface of the egg yolk. This provides a robust two dimensional system on which amniote development can be interrogated.

Additionally, the rapid development of the cardiovascular system in the avian is convenient for investigation of the initial events that drive both cardiogenesis and formation of the vasculature (Fig 1). Within the first $24-30 \mathrm{hrs}$ of incubation, blood and vascular development initiates both in the form of extra-embryonic blood islands and intra-embryonic endothelial cell specification and differentiation (Pardanaud et al., 1996). The first major blood vessels of the embryo, the paired dorsal aorta, have formed by 30-35 hrs of development (Pardanaud et al., 1996; Reese et al., 2004; Bressan et al., 2009; Garriock et al., 2010), and a beating heart is apparent by $38-42 \mathrm{hrs}$ of development (Patten and Kramer, 1933). Furthermore, the embryo remains largely transparent as many of the primary organ rudiments including the heart, liver, lung, kidney, eye, brain and spinal cord initiate their morphogenetic development, making observation organ specific vascular formation possible with both simple and advanced microscopy techniques.

\section{Materials}

\subsection{Fertilized Eggs}

Fertilized Chicken eggs (Gallus gallus) or Japanese quail (Cortonix japonicum) can be obtained from local farms. Alternatively, pathogen free avian eggs can be ordered from vendors including Charles River. Once obtained eggs can be stored at 12-16 C for up to one week before being transferred to a humidified incubator.

\subsection{Common Buffers, chemicals}

1. Many buffers and reagents used in standard cell culture protocols are compatible with avian embryonic isolation and manipulation. For instance Phosphate Buffered Saline $(0.1 \mathrm{~g} / \mathrm{L} \mathrm{CaCl} 2,0.1 \mathrm{~g} / \mathrm{L} \mathrm{MgCl} 2,0.2 \mathrm{~g} / \mathrm{L} \mathrm{KCl}, 0.2 \mathrm{~g} / \mathrm{L} \mathrm{KH} 2 \mathrm{PO} 4,8.0 \mathrm{~g} / \mathrm{L} \mathrm{NaCl}$, $2.16 \mathrm{~g} / \mathrm{L} \mathrm{Na} 2 \mathrm{HPO} 4)$ is often used for the isolation of tissues or cells for culture.

2. Simple Saline $(7.19 \mathrm{~g} / \mathrm{L} \mathrm{NaCl})$ is used to make albumen agar plates for modified New Culture.

3. Tyrode's Solution $(0.265 \mathrm{~g} / \mathrm{L} \mathrm{CaCl} 2,0.05 \mathrm{~g} / \mathrm{L} \mathrm{MgCl} 2,0.2 \mathrm{~g} / \mathrm{L} \mathrm{KCl}, 8 \mathrm{~g} / \mathrm{L} \mathrm{NaCl}$, $0.05 \mathrm{~g} / \mathrm{L}$ NaH2PO4, $1 \mathrm{~g} / \mathrm{L}$ Glucose) or Hank's Balanced Salt Solution $(0.185 \mathrm{~g} / \mathrm{L}$ $\mathrm{CaCl} 2,0.2 \mathrm{~g} / \mathrm{L} \mathrm{MgCl} 2,0.4 \mathrm{~g} / \mathrm{l} \mathrm{KCl}, 0.06 \mathrm{~g} / \mathrm{L} \mathrm{KH} 2 \mathrm{PO} 4, * .0 \mathrm{~g} / \mathrm{L} \mathrm{NaCl}, 1 \mathrm{~g} / \mathrm{L}$ Glucose, $0.09 \mathrm{~g} / \mathrm{L}$ Na2HPO4) buffered with $15-25 \mathrm{mM}$ Hepes are also commonly used for in ovo manipulation and isolation.

4. Pannett Compton's Solution ( $12.11 \mathrm{~g} / \mathrm{L} \mathrm{NaCl}, 1.55 \mathrm{~g} / \mathrm{L} \mathrm{KCl}, 0.77 \mathrm{~g} / \mathrm{L} \mathrm{CaCl}$, $1.27 \mathrm{~g} / \mathrm{L} \mathrm{MgCl} 2)$ is recommended for the isolation and early culture of the avian blastoderm. 
5. Solutions of $1-10 \%$ India Ink in a buffered salt solution can be injected into the yolk below the embryo during in ovo manipulations to aid in visualizing tissue.

6. Similarly Fast Green (Sigma) prepared at a final concentration of $1 \%$ is frequently mixed into reagents to be microinjected into the embryo to help determine the extent of the injected area.

\subsection{Microsurgical tools}

1. Tools for microsurgical techniques in the embryo vary depending on the need of the investigator. In our experience, spring balanced dissecting scissors with a blade length of 2-3mm (Ex. Cat Number 15000-08, Fine Scientific Instruments, Foster City, Ca) work well for general dissection, while Ultra fine Clippers (Cat Number 15200-00, Fine Scientific Instruments, Foster City, Ca) are better suited for more delicate manipulations.

2. Choice of forceps for micromanipulation can be difficult to gauge prior to attaining hands on experience with various manufactures. In general a relatively blunt pair and a fine pair are recommended. For example a combination of Dumont \#5 and Dumont \#5SF forceps with tip dimensions of $0.1 \times 0.06 \mathrm{~mm}$ and $0.025 \times 0.0005 \mathrm{~mm}$ respectively provide adequate flexability to preform a variety of embryonic manipulations.

3. Pulled Glass Needles can be used for for very fine micro-dissections in the embryo. Glass needles are not as bulky as forceps or scissors and therefore can be used to access regions of the embryo with minimal damage to surrounding tissues. Thin walled glass capillaries (OD 1/ ID $0.75 \mathrm{~mm}$, World Precision Instruments) are stretched on a vertical puller (Kopf Model 720, David Kopf instruments, Tununga, Ca) to achieve the desired length needle. These needles can then be coated with 5\% BSA or silicone (Sigmacoat, Sigma) to prevent embryonic tissues from sticking to the glass.

4. Similarly, sharpened tungsten needles can be used for very fine manipulations.

Tungsten wire can be sharpened by applying and electrical current to the wire while suspending or partially submerging the wire in a $1 \mathrm{~N} \mathrm{NaOH}$ bath (Conrad et al. 1993).

5. Finally special attention must be paid to the tools used to transfer cells or tissue from one region of an embryo to another (or into a host embryo). Small clusters of cells tend to stick to metal forceps or plastic pipets making transplantation difficult. Glass transfer pipets such as Dummond Wiretol pipets (Dummond Scientific Company, Cat number 5-000-2005) work very well in this regard.

\subsection{Beads/Cells}

1. Crosslinked agarose beads such as Affi-Gel Blue (Biorad) are sufficient for the delivery of many growth factors and/or pharmacological reagents. However, the relative adhesiveness of the factor being introduced should be considered when choosing a bead substrate. 
2. Cos $1 / 7$ cells can be commercially obtained from vendors such as ATCC. These cells can be cultured in hanging drops in order to form clusters that can be engrafted into the embryo.

3. Similarly ATCC supplies lines such as Phoenix cells, which are a stable cell line that expresses genes required for viral packaging, and D17 cells which can be used to check viral titters.

\subsection{Electroporation/Viral equipment}

Equipment for microinjection of viral particles and/or electroporation is presented in Fig 3 .

Below are is a list of major equipment and manufacturers:

1. Stereo microscope - Leica MZ6 (Leica Microsystems)

2. Electroporator - Nepa21 (Nepagene)

3. Electrodes - Made from platinum wire (Alfa Aesar $0.5 \mathrm{~mm}$ or $0.25 \mathrm{~mm}$ diameter)

4. Glass needles - (World Precision INstruments)

5. Pressure Injector - Ependorf Femtojet (Ependorf)

6. manipulators - Leica micromanipulator (Leica Microsystems)

7. Remote injector - Ependorf Transmaster NK (Ependorf)

\subsection{Egg Incubator}

A variety of incubators are available for avian embryological studies. Eggs are typically incubated at temperatures of $38+/-1 \mathrm{C}$ and sufficient humidity should be maintained to prevent embryo drying. For incubation to later stages of development incubators equipped with automatic rocking platforms are preferred. Smaller format styrofoam of Lucite incubators (ex. Hova-Bator Model 1602N - GQFmfg, Savannah Ga, or Marsch Automatic INcubator, Lyon Electrical Company, Chula Vista Ca) can be used for to incubate up to 48 eggs at once. When plugged into traceable outlet controllers (Fisher Scientific) theses incubators also allow for the timing of incubation to be precisely set.

\section{Methods: Techniques for handling the embryo}

A variety of experimental manipulations are well tolerated in the developing avian embryo. While dozens of protocols exist for basic manipulation, most are variations of three basic systems: in ovo manipulation, shell-less culture of the embryo, and New Culture (Fig 2). The choice of which system should be used depends on the the question being addressed and the developmental window during which the manipulations need to be made. As such, these features must be evaluated by the researcher prior to determining the proper technique to be utilized. Below the pros and cons of each system will be briefly discussed.

\subsection{In ovo manipulation}

1. As described above embryos can be brought to a desired developmental stage with a high degree of reproducibility based on the timing of incubation. As the embryo floats on the top of the yolk the position of the embryo within the egg can also be 
controlled by the angle at which the egg is incubated. Once the the stage at which an investigator intends to manipulate the embryo is reached, the egg can be removed from the incubator and "windowed." This process involves cutting a small hole or window in the egg shell above the embryo (Fig 2A). Often a syringe is used to remove excess albumin so that the embryo will sit lower in the egg helping to prevent the embryo from sticking to the shell following re-incubation. Following manipulation, the hole in the egg shell can be resealed either using parafilm or scotch tape and the embryo can be replaced in the incubator to develop further.

2. In ovo manipulations have the advantage of high viability in long term postmanipulation, incubation. Using this technique embryos can be developed through hatching. Depending on the nature of the experiment, in ovo manipulation also results fewer developmental abnormalities than other techniques described below. However, manipulating the embryo in ovo can often be challenging. In particular grafting, transplantation, and fine micro-dissection can be difficult as the yolk in the the embryo can rotate during experimentation, and puncture of the embryo (exposing the yolk) can lead to lethality. Furthermore, it is often difficult to preform high resolution microscopy on embryos in ovo.

\subsection{Shell-less culture}

1. removing the embryo from the shell alleviates some of the above challenges. In this technique the embryo, yolk, and albumen are transferred to an artificial vesicle such as a petri dish, weigh boat, or plastic wrap "hammock" (Dunn, 1991) (Fig 2B). Once outside the shell the embryo is allowed to develop ex ovo and can be reincubated until late gestation.

2. This system has several advantages as the accessibility of the embryo is greatly improved outside of the shell. Whereas the position of the the embryo relative to the shell can preclude several types of manipulations in ovo, the shell-less system allows the investigator to target a greater variety of tissues in the embryo and is particularly useful for techniques the related to the extra embryonic vasculature of the chorioallantoc membrane (which will be discussed below). Moreover, shell-less culture is much more amenable to live imaging than in ovo techniques. However, long term viability is often lower in shell-less cultures and great attention must be paid to preventing the embryo from drying out.

\subsection{New Culture}

1. In 1955 D.A.T. New developed a system for ex ovo culture of avian embryos in which the early blastoderm was removed from the yolk and cultured on a piece of vitelline membrane stretched across a glass ring (New, 1955). This technique has been modified by several additional investigators over the years with isolation using paper rings and culture on albumen agar plates representing a particular useful advancement, simplify both the removal and positioning of the embryo (Chapman et al., 2001) (Fig 2C). 
2. Using this technique embryos can be isolated at early blastoderm stages and cultured through heart looping stages (approx. $68 \mathrm{hrs)}$. This is an extraordinarily powerful system as it allows for high resolution examination of early developmental processes including those required for vascular development such as gastrulation, blood island formation, endothelial cell formation, vasculogenesis, angiogenesis, and heart development in situ. Again as these event occur while the embryo is still largely a two dimensional embryonic disk and the vast majority of yolk has been removed from the embryo, New culture is ideal fro detailed embryonic observation. Furthermore, many experimental approaches which would be difficult to execute in ovo or in shell-less culture, such as fine micro-surgery, can readily be preformed in New culture. The major draw back of this system, however, is that embryos typically do not advance beyond the 3rd day of development in New culture meaning it is no appropriate to study later developmental processes.

\subsection{Ablation, Transplantation, and Chimeras}

1. As discussed above, one of the principle strengths of the avian model system is its amenability to physical manipulation. Ablation experiments are often used to determine the capacity of one tissue to induce and/or suppress fate decision in adjacent tissues. In these studies cells or tissue are removed during a specific temporal window and the embryo is then allowed to further develop. The resultant phenotype is then examined. Such approaches are advantageous because the do not rely on any previous knowledge of the molecular composition of the tissue being removed. As such the capacity of one tissue to influence an adjacent tissue can be rapidly investigated leading to future studies related to the mechanistic nature of the inductive/suppressive interaction. Furthermore, as the window of the manipulation is defined by the timing of the manipulation, no ambiguity exits as to when inductive interactions are occurring.

2. Transplantation experiments are often used in conjunction with ablation studies. As the term suggests donor tissue from one embryo is removed and placed either into a host embryo or a host region within the same embryo. In these studies the transplanted tissue can be transplanted into either the same position at the same stage from which it was isolated from the donor embryo (isochronic-isotopic), placed into a different position at a different stage in the host embryo (heterochronic-heterotopic), or any variation thereof. Transplantation studies are used for a variety of purposes such as determining inductive/suppressive interaction, and when combined with some form of cell tracing, can be used to determine migration, fate contributions, and growth patterns.

3. Chimera generation is a variation on the basic idea of transplantation studies. Grafting of chick cells into quail embryos or vice versa represents the most common form of chimera generation in the avians. The initial value of this strategy was that the grafted cells could be easily distinguished from the host tissue. Quail nuclei can be easily distinguished from chick nuclei due to the presence of foci of heavily condensed heterochromatin that can be detected histologically (Le Douarin, 
1973). Furthermore, a variety of species-specific antibodies have been generated including the Quail/Chick perinuclear antibody (QCPN) which reacts to quail cells and QH1, an antibody that recognizes a glycoprotein on the surface of quail endothelial cells and does not cross-react with chick endothelium (Peault et al., 1983; Pardanaud et al., 1989). As such the behavior of individual quail cells in relationship to the host environment in which they are placed can be traced.

4. Of interest, other forms of chimeric embryo generation have been used to great effect in the avian system. Quail-duck chimeras should be mentioned due to several unique features of this manipulation. As the gestational period of the quail and chick diverge considerably (17 days for quail and 28 days for duck) and the size for the organisms differ greatly, questions related to intrinsic vs extrinsic control of developmental timing and growth control are well suited to combining quail and duck tissue (Schneider and Helms, 2003; Tucker and Lumsden, 2004; Eames and Schneider, 2005). Additionally, mouse embryonic tissue readily incorporates into chick embryos. As such mouse genetic interventions can be combined with chick physical manipulation in chick-mouse chimeras ((Fontaine-Perus and Cheraud, 1996; Serbedzija and McMahon, 1997; Pudliszewski and Pardanaud, 2005).

\subsection{Cell/bead implantation}

1. While the above techniques have been classically utilized to determine tissue-tissue interactions, it is often the goal of modern developmental biologists to identify the molecular signals that influence cell fate decisions in the embryo. This is particularly true in the study of vascular patterning, as how endothelial cells decide to form blood vessels in certain regions while adjacent regions remain avascular has far reaching implications on our fundamental understanding cardiovascular homeostasis. In this capacity the avian embryo provides a convenient system to monitor the how signaling factors to alter endothelial cell behavior in situ. An approach that has been adopted by many investigators for this purpose is to soak biologically inert micro-beads in signaling factors and implant those beads into the embryo (Bates et al., 2003; Bouvrée et al., 2008; Cox and Poole, 2000; Finkelstein and Poole, 2003; Nimmagadda et al., 2005; Tickle et al., 1985). With the commercial availability of many signaling peptides and pharmacological reagents, this strategy is particularly attractive as it requires little front end investment on the part of the investigator (i.e construct design and validation for genetic manipulation), and the positioning of the intervention can be controlled by the implantation site. Beads consisting of a variety of substrates can be made or purchased and coated with differing concentrations of growth factors. These beads are then surgically implanted into the embryo and the response of the surrounding tissue is monitored. While these experiments are relatively quick, bead based experiments suffer from several limitations. For example, it is difficult to predict beforehand or measure experimentally the concentration gradient produced by exogenously introduced factors, the distance which the factor travels in the embryo, or the timing of release from the bead, all of which may complicate interpretation. Additionally, bead implantation has the disadvantage of causing damage and or 
physical deformation to the surrounding tissue, which may result in off target effects.

2. A popular alternative approach to bead implantation is the introduction of genetically modified cells into the embryo (Bressan et al., 2013; Reese et al., 2004). Typically cell lines, such as Cos cells (derived from simian kidney tissue), which have had a gene of interest introduced are used for this purpose. Cos cells contain genetic material from the SV40 virus, meaning they are capable of propagating transiently transfected plasmids containing an SV40 origin of replication (Gluzman, 1981; Li and Kelly, 1984). As a results Cos cells display long-term, high production of genetically introduced factors. Furthermore, when cultured in hanging drops Cos cells form tight clusters (pellets) of various sizes which can be manually selected by investigators for implantation into the embryo. As an extension of this technique, micro-injection of cells into the embryo as a substitute to physical engraftment, has been used (Bressan et al., 2013; Mikawa et al., 1992). This approach is gentler than physical implantation as less damage is done to the host embryo, the number of cells introduced can be more finely controlled, and greater precision in targeting can be achieved.

\subsection{Cell Labeling}

1. A critical component of understanding the developmental history of a terminally differentiate cell type is identifying both the location and fate potentials of their precursors. This information provides critical insight into the timing and ultimate mechanisms that drive fate decisions. While modern molecular biology allows for genetic based labeling strategies during embryonic development (such as promoter specific expression of Cre recombinase), in many situations direct cell labeling approaches remain preferable. This is especially true when little information is available regarding the molecular composition of the progenitor pool from which a cell type of interest arises. In this context, the avian embryo is a very powerful system for analyzing fate relationships due to the ease in which cells can be directly tagged in ovo and the high number of tagging experiments that can be preformed in a relative short period of time. Furthermore, while more laborious than genetic techniques employed in other species, the timing and location of label introduction is determine by the investigator during avian labeling experiments which greatly simplifies interpretation of results.

2. Direct cell tracing experiments in the avian embryo can broadly be broken down into two categories: fate mapping and lineage analysis. While these two approaches are both reliant on the labeling of progenitor cells at one stage of development and examination of their fate at subsequent stages, it must be noted that the goals of the two approaches are often quite different. In general fate mapping refers to the systematic labeling of cells across a broad region of the embryo to determine the distribution of progenitor populations for one or more cell types prior to their differentiation. Fate mapping studies essentially depend on three principle components: 1) a robust method for visualizing labelled cells, 2) a technique for 
determine the initial position of labelled across different embryos, and 3) a scoring system from which end-state fate can be determined.

3. Lineage analysis, on the other hand, is used to label cells with in a specific region of the embryo in order to determine the cell types that emerge form this progenitor pool. In lineage analysis, the precise position of the initially labelled cell is not critical (given that it is generally understood), however the clonality of the labelled population is paramount. For example, if the initially tagged population contains progenitor cells which have already undergone fate segregation, and the labeling technique is broadly applied, the distribution of fates present at the end of the experiment will be uninformative. This is due to the fact that lineage analysis is by nature retrospective, and therefore the investigator would be unable to differentiate between a single progenitor cell giving rise to a variety of cell types or multiple cells (of divergent fates) initially being tagged. Therefore, both experimental and/or statistical strategies for determining the clonality of labelled cells must be employed to demonstrate that the labeling technique is appropriate. A labeling technique frequently used for chick lineage analysis is the introduction of low titer replication incompetent retroviruses. These viruses can be microinjected at concentrations as low as 1-10 virons per embryo. Following infection the viral genome (containing a label) is integrated into the infected cell resulting in labeling of all of the progeny of that cell. The replication incompetence of the virus prevents lateral transmission of the cell label, therefore labelled progeny must arise from the initial infection. Clonality of the label can then be determined using a variety of techniques (Cepko et al., 1998; Mikawa et al., 1992; Cohen-Gould and Mikawa, 1996). Some examples include, mixing of viruses with different cell labels to calculate the probability multiple infections in a single embryo, statical evaluation of number of labelled cells related to the average cycle cycle, and sequencing based evaluation of the integration site in the host genome.

4. The quality and variety of reagents available for fate mapping and lineage analysis studies has grown immensely over the past 20 years. Coupled with live imaging modalities which are becoming increasingly accessible, the resolution with which we can trace the timing and location of fate decisions within the overall morphogenetic events of embryogenesis is continually improving.

\subsection{Somatic Transgenesis}

1. The capacity to create genetically modified organisms has proven one of the most significant advances in the recent history of biomedical and embryological research. In many ways the avian model system has lagged behind other model organisms in the current genetic age. This has been in large part do to several technical limitations inherent in avian embryology. Chief among these is that while avian germ-line transgenic animals can be generated (Harvey et al., 2002; McGrew et al., 2004; Mozdziak et al., 2003; Salter et al., 1987; Scott and Lois, 2005; Pain et al., 1996; Petitte et al., 1990; van de Lavoir et al., 2006; Zhu et al., 2005; Chapman et al., 2005), most institutes are not designed to accommodate avian husbandry in the ways they can currently handle other genetic model systems. Furthermore, 
researchers only have access to the avian embryo once it has been laid. As a result, early genetic manipulations that can be preformed in organisms in which fertilization and the first cleavage events occur outside the mother (including Xenopus and zebrafish) are not possible in avians.

2. Despite these limitations continued advances in mosaic transgenesis are beginning to establish the avian as a bonafide model in which genetic gain and loss of functions can be routinely preformed. Gain and loss of function studies in the avian embryo mirror techniques used in other model systems, with examples including construct based over expression of functional proteins, expression of dominant negative proteins, and introduction of morpholinos or shRNA for gene knockdown (Chen et al., 2004; Chesnutt and Niswander, 2004; Das et al., 2006; Itasaki et al., 1999; Katahira and Nakamura, 2003; Kos et al., 2003; Krull, 2004; Luo and Redies, 2004; Nakamura et al., 2004; Ogura, 2002; Swartz et al., 2001). What is unique in the avian system, however, is the ability to focally introduce genetic manipulations only at specific regions of the embryo during very precise developmental stages. This allows for direct observation of phenotypic changes and can be advantageous to germ-line transgenesis in some circumstances as this approach can help to minimize off-target effects.

3. Classically, genetic manipulation in avians is preformed using retroviral mediated somatic transgenesis (Ishii et al., 2004) (Fig 3B,C). As described above for lineage analysis, viral particles are locally injected into a region of the embryo. Following infection, the retroviral RNA genome is reverse transcribed into a double stranded DNA which is integrated into the host genome. This results in stable expression of the genes engineered into the virus by the host cell and its descendants. Retroviral expression systems consist of replication-competent and incompetent varieties. Replication competent retrovirus, such as RCAS, contain the critical genes required for viral propagation (gag, pol, and env), allowing for lateral transmission of the infection after the initial introduction of the virus. While this can increase the overall size of effected tissue, it is not possible to differentiate between primary infected cells and those infected secondarily and this must be taken into account during interpretation of results. Alternatively, replication incompetent retroviruses have been engineered to lack the gag, pol, and env, but retain the cis elements required for viral packaging, transcription, and integration. As the gag, pol, and env genes have been removed, replication incompetent retrovirus can also be used to shuttle larger constructs into the host genome (approx. $2 \mathrm{~kb}$ for competent vs approx. $7 \mathrm{~Kb}$ for incompetent retrovirus) (Ishii et al., 2004). Only vertical transmission of the introduced gene is possible with replication-incompetent retroviruses, which usually results in fewer infected cells. While remaining an extremely powerful technique for in vivo genetic manipulations, the limitations of retro-viral mediated somatic transgenesis should be noted. Retroviral production can be time consuming as viral vectors must be constructed, transfected into packaging cell lines, viral particles must be produced by those cells, harvested, and viral titer must be determined prior to being available for injection into the embryo. Infection efficiency may vary across different cell types in the embryo. Infected 
cells must undergo a cell division in order to integrate the viral genome making manipulation of post mitotic or slowly dividing cells difficult. Infected embryos are mosaic and variation from embryo to embryo often requires high numbers for analysis. Finally, the integration in the host genome will vary from cell-to-cell and from embryo-to-embryo which can also lead to unforeseen variation.

4. Adenoviral based delivery of DNA into avian cells has also been used for over expression in avians (Fisher and Watanabe, 1996; Watanabe et al., 1998).

Following infection, the double stranding DNA genome of these viruses is transported into the nuclease of the host cell and sequesters the host transcriptional machinery for expression. As such, adenoviruses provide quick, high copy number expression of exogenous genes, and can infect post-mitotic or slowly dividing cells. However, as the adenoviral genome is not typically incorporated into the host genome and it is exponentially diluted with successive cell divisions. Furthermore, the viral particles must still be generated and harvested prior to use.

5. Direct electroporation of DNA plasmids into avian tissue has been used to circumvent some of the limitations inherent in viral based approaches. In this technique a series of low voltages, square electric pulses, are applied to the embryo (Muramatsu et al., 1997) (Fig 3D,E). This opens pores in the plasma membrane of cells within the electrical field and drives the transport of charged molecules (such as DNA) into the cytosol. When the pulses are removed the pores repair themselves. By controlling the site of DNA application and positioning of electrodes, electroporation can be used to introduce high plasmid copy numbers into focused regions of the embryo. Electroporation does not require a cell division prior to expression and therefore exogenous genes can be detected very rapidly (within 3hrs). One of the major limitations of this system has been that plasmid copy number is diluted with cell division. However, the recent use of Tol2 and piggyBAC expression vectors have alleviated this issue (Sato et al., 2007; Sanders et al., 2013). These plasmids contain an expression construct flanked by transposable elements. When co-electroporated with a transposase enzyme the gene within the transposable elements can be integrated into the host genome resulting in long-term stable expression (Kawakami, 2005). Due to its advantages, electroporation is quickly becoming the technique of choice for genetic manipulation in the avian system. Great care must still be taken when analyzing results obtained via electroporation, however, as differences in plasmid copy number and transfection efficiency can vary from embryo-to-embryo meaning robust control experiments must be designed and executed.

\subsection{Genomics}

6. Extremely efficient genomics and bioinformatics tools are currently available for a variety of model systems, and avian embryology has begun to adopt these techniques to great success. For example, databases such as those hosted by the University of Arizona (Geisha) (Antin et al., 2013; Bell et al., 2004), provide powerful resources for the pattern of gene expression during embryogenesis. Furthermore, the advent of next generation sequencing technologies such as 
dSAGE and RNAseq provide whole transcriptome quantification and profiling not previously available for studies in avians. Prior microarray-based large format expression profiling required the construction or use of preexisting chips with cDNA or oligonucleotide libraries spotted at a specific positions. Due to poor availability of avian specific chips, microarray studies were limited and cumbersome to all but a select few laboratories working in avian species. However, techniques such as dSAGE and RNAseq allow for massively parallel shotgun sequencing of total mRNA isolated from embryonic tissue. Bioinformatics is then used to determine the identify and relative levels of mRNA species within the sample. Thus, no species specific cDNA library or chip is required. Accordingly, avians represent an exciting system for these global RNA sequencing techniques as their the unparalleled accessibility as an amniote model system will uniquely allow for the detailed evaluation of expression changes across finely separated developmental stages, within closely opposed progenitor fields, and following experimental manipulation, through simple isolation and comparison of embryonic tissues.

\subsection{Chorioallantoic Membrane Assay (CAM)}

7. During avian development the mesodermal layers of the allantois and chorion fuse to form the chorioallantoic membrane (CAM). This structure rapidly expands around the embryo generating a rich vascular network that provides an interface for gas and waste exchange. The CAM is an ideal in vivo system for studying vascular network formation as it is a thin, transparent, two dimensional surface that is easily accessible (especially in shell-less culture). Furthermore, CAM development proceeds the establishment of a functional immune system meaning that foreign cells (including tumors cells) can be cultured directly on the CAM to analysis vascular invasion of these tissues ((Armstrong et al., 1982; Auerbach et al., 1976; Dagg et al., 1956; Durupt et al., 2012; Knighton et al., 1977; Kunzi-Rapp et al., 2001). As such, the capacity of the CAM vasculature to sprout or regress in response to ectopic cells and/or factors has been widely as a vascular assay system. Using this system the angiogenic or anti-angiogenic potency of growth factors and pharmacological reagents can be quickly and reliable determined in a low-cost in vivo system (Ribatti et al., 1996). Molecular signals that initiate tumor neovascularization and metastasis are also frequently studied using the CAM. Consequently, the CAMs accessibility and simplicity, in regards of experimental execution, provide an important in vivo functional assay through which the mechanisms of vascular sprouting can be examined.

\section{Conclusion}

In this chapter, we have covered some basic principles of avian experimental embryology, with the hope of introducing readers to the utility, diversity, and limitations of the avian model system. As a higher vertebrate model of development, avians uniquely allow for the simultaneous investigation of multiple levels of biology (molecular through organismal) via the merger of classical physical manipulations with modern molecular biology techniques. 
In many ways, it is this elegant blend of simplicity and complexity that has kept investigators returning to the avian embryo for the last 2000 years.

\section{Acknowledgement}

The work was supported in part by the NIH-NHLBI (1K99HL122360-01 to M.B. and HL078921, HL092429, HL093566, HL112268, HL122375 to T.M.)

\section{References}

Antin PB, Yatskievych TA, Davey S, Darnell DK. GEISHA: an evolving gene expression resource for the chicken embryo. Nucleic Acids Research. 2013

Armstrong PB, Quigley JP, Sidebottom E. Transepithelial Invasion and Intramesenchymal Infiltration of the Chick Embryo Chorioallantois by Tumor Cell Lines. Cancer Research. 1982

Aristotle; Peck, AL. Loeb Classics. Vol. XIII. Harvard University Press; Cambridge: 1943. Generations of Animals.. transl.

Auerbach R, Kubai L, Sidky Y. Angiogenesis Induction by Tumors, Embryonic Tissues, and Lymphocytes. Cancer Research. 1976

Bates D, Taylor GI, Minichiello J, Farlie P, Cichowitz A, Watson N, Klagsbrun M, Mamluk R, Newgreen DF. Neurovascular congruence results from a shared patterning mechanism that utilizes Semaphorin3A and Neuropilin-1. Developmental Biology. 2003; 255:77-98. [PubMed: 12618135]

Bell GW, Yatskievych TA, Antin PB. GEISHA, a whole-mount in situ hybridization gene expression screen in chicken embryos. Dev. Dyn. 2004; 229:677-687. [PubMed: 14991723]

Bouvrée K, Larrivée B, Lv X, Yuan L, DeLafarge B, Freitas C, Mathivet T, Bréant C, Tessier-Lavigne M, Bikfalvi A, et al. Netrin-1 inhibits sprouting angiogenesis in developing avian embryos. Developmental Biology. 2008; 318:172-183. [PubMed: 18439993]

Bressan M, Liu G, Mikawa T. Early Mesodermal Cues Assign Avian Cardiac Pacemaker Fate Potential in a Tertiary Heart Field. Science. 2013; 340:744-748. [PubMed: 23519212]

Bressan M, Davis P, Timmer J, Herzlinger D, Mikawa T. Notochord-derived BMP antagonists inhibit endothelial cell generation and network formation. Developmental Biology. 2009; 326:101-111. [PubMed: 19041859]

Cepko CL, Ryder E, Austin C, Golden J, Fields-Berry S, Lin J. Lineage analysis using retroviral vectors. Methods. 1998; 14:393-406. [PubMed: 9608510]

Chapman SC, Collignon J, Schoenwolf GC, Lumsden A. Improved method for chick whole-embryo culture using a filter paper carrier. Dev. Dyn. 2001; 220:284-289. [PubMed: 11241836]

Chapman SC, Lawson A, Macarthur WC, Wiese RJ, Loechel RH, Burgos-Trinidad M, Wakefield JK, Ramabhadran R, Mauch TJ, Schoenwolf GC. Ubiquitous GFP expression in transgenic chickens using a lentiviral vector. Development. 2005; 132:935-940. [PubMed: 15673573]

Chen H, Shi S, Acosta L, Li W, Lu J, Bao S, Chen Z. BMP10 is essential for maintaining cardiac growth during murine cardiogenesis. 2004

Chesnutt C, Niswander L. Plasmid-based short-hairpin RNA interference in the chicken embryo. Genesis. 2004; 39:73-78. [PubMed: 15170691]

Coffin JD, Poole TJ. Embryonic vascular development: immunohistochemical identification of the origin and subsequent morphogenesis of the major vessel primordia in quail embryos. Development. 1988; 102:735-748. [PubMed: 3048971]

Cohen-Gould L, Mikawa T. The fate diversity of mesodermal cells within the heart field during chicken early embryogenesis. Developmental Biology. 1996; 177:265-273. [PubMed: 8660893]

Cox CM, Poole TJ. Angioblast differentiation is influenced by the local environment: FGF-2 induces angioblasts and patterns vessel formation in the quail embryo. Dev. Dyn. 2000; 218:371-382. [PubMed: 10842363]

Dagg CP, Karnofsky DA, Roddy J. Growth of Transplantable Human Tumors in the Chick Embryo and Hatched Chick. Cancer Research. 1956 
Das RM, Van Hateren NJ, Howell GR, Farrell ER. A robust system for RNA interference in the chicken using a modified microRNA operon. Developmental. 2006

Dunn, B,E. Methods for Shell-less and semi-shell-less culture of avian and reptile embryos. Cambridge University Press; 1991. p. 409-418.

Durupt F, Koppers-Lalic D, Balme B, Budel L, Terrier O, Lina B, Thomas L, Hoeben RC, RosaCalatrava $\mathrm{M}$. The chicken chorioallantoic membrane tumor assay as model for qualitative testing of oncolytic adenoviruses. Cancer Gene Ther. 2012; 19:58-68. [PubMed: 22015640]

Eames BF, Schneider RA. Quail-duck chimeras reveal spatiotemporal plasticity in molecular and histogenic programs of cranial feather development. Science Signaling. 2005

Finkelstein EB, Poole TJ. Vascular endothelial growth factor: A regulator of vascular morphogenesis in the Japanese quail embryo. Anat. Rec. 2003; 272A:403-414.

Fisher SA, Watanabe M. Expression of exogenous protein and analysis of morphogenesis in the developing chicken heart using an adenoviral vector. Cardiovascular Research. 1996

Fontaine-Perus J, Cheraud Y. Int J Dev Biol - Developmental potentialities of the mouse neural tube grafted in chick embryo. The International Journal. 1996

Garriock RJ, Czeisler C, Ishii Y, Navetta AM, Mikawa T. An anteroposterior wave of vascular inhibitor downregulation signals aortae fusion along the embryonic midline axis. Development. 2010; 137:3697-3706. [PubMed: 20940228]

Gluzman Y. SV40-transformed simian cells support the replication of early SV40 mutants. Cell. 1981; 23:175-182. [PubMed: 6260373]

Harvey AJ, Speksnijder G, Baugh LR, Morris JA, Ivarie R. Expression of exogenous protein in the egg white of transgenic chickens. Nature Biotechnology. 2002; 20:396-399.

Ishii Y, Reese DE, Mikawa T. Somatic transgenesis using retroviral vectors in the chicken embryo. Dev. Dyn. 2004; 229:630-642. [PubMed: 14991718]

Itasaki N, Bel-Vialar S, Krumlauf R. I Shocking/' developments in chick embryology: electroporation and : in ovo: gene expression : Abstract : Nature Cell Biology. Nat. Cell Biol. 1999; 1:E203-E207. [PubMed: 10587659]

Katahira T, Nakamura H. Gene silencing in chick embryos with a vector-based small interfering RNA system. Dev Growth Differ. 2003; 45:361-367. [PubMed: 12950277]

Kawakami K. Transposon tools and methods in zebrafish - Kawakami - 2005 - Developmental Dynamics - Wiley Online Library. Dev. Dyn. 2005

Knighton D, Ausprunk D, Tapper D. Avascular and vascular phases of tumour growth in the chick embryo. British Journal of. 1977

Kos R, Tucker RP, Hall R, Duong TD, Erickson CA. Methods for introducing morpholinos into the chicken embryo. Dev. Dyn. 2003; 226:470-477. [PubMed: 12619133]

Krull CE. A primer on using in ovo electroporation to analyze gene function. Dev. Dyn. 2004; 229:433-439. [PubMed: 14991698]

Kunzi-Rapp K, Genze F, Küfer R, Reich E, Hautmann RE, Gschwend JE. Chorioallantoic membrane assay: vascularized 3-dimensional cell culture system for human prostate cancer cells as an animal substitute model. J. Urol. 2001; 166:1502-1507. [PubMed: 11547121]

Le Douarin N. A biological cell labeling technique and its use in experimental embryology. Developmental Biology. 1973

Li JJ, Kelly TJ. Simian virus 40 DNA replication in vitro. Proceedings of the National Academy of Sciences. 1984; 81:6973-6977.

Luo J, Redies C. Overexpression of genes in Purkinje cells in the embryonic chicken cerebellum by in vivo electroporation. Journal of Neuroscience Methods. 2004

McGrew MJ, Sherman A, Ellard FM, Lillico SG, Gilhooley HJ, Kingsman AJ, Mitrophanous KA, Sang H. Efficient production of germline transgenic chickens using lentiviral vectors. EMBO Rep. 2004; 5:728-733. [PubMed: 15192698]

Mikawa T, Borisov A, Brown AMC, Fischman DA. Clonal analysis of cardiac morphogenesis in the chicken embryo using a replication-defective retrovirus: I. Formation of the ventricular myocardium. Dev. Dyn. 2006; 193:11-23. [PubMed: 1540702] 
Mozdziak PE, Borwornpinyo S, McCoy DW, Petitte JN. Development of transgenic chickens expressing bacterial ?-galactosidase. Dev. Dyn. 2003; 226:439-445. [PubMed: 12619130]

Muramatsu T, Mizutani Y, Ohmori Y. Comparison of Three Nonviral Transfection Methods for Foreign Gene Expression in Early Chicken Embryosin Ovo. ... And Biophysical Research .... 1997

Nakamura H, Katahira T, Sato T, Watanabe Y. Gain- and loss-of-function in chick embryos by electroporation. Mechanisms of .... 2004

Needham, J. A History of Embryology. Abelard-Schuman; New York: 1959.

Hampe A. Role of mesoderm and ectoderm of leg bud in exchanges between duck and chicken. C.R. Hebd Seances Acad. Sci. 1957; 244:3179-3183.

New DAT. A New Technique for the Cultivation of the Chick Embryo in vitro. Journal of Embryology and Experimental Morphology. 1955

Nimmagadda S, Geetha Loganathan P, Huang R, Scaal M, Schmidt C, Christ B. BMP4 and noggin control embryonic blood vessel formation by antagonistic regulation of VEGFR-2 (Quek1) expression. Developmental Biology. 2005; 280:100-110. [PubMed: 15766751]

Noden DM. Embryonic origins and assembly of blood vessels. Am. Rev. Respir. Dis. 1989; 140:10971103. [PubMed: 2478056]

Ogura T. In vivo electroporation: a new frontier for gene delivery and embryology - Ogura - 2002 Differentiation - Wiley Online Library. Differentiation. 2002

Pain B, Clark ME, Shen M, Nakazawa H, Sakurai M, Samarut J, Etches RJ. Long-term in vitro culture and characterisation of avian embryonic stem cells with multiple morphogenetic potentialities. .... 1996

Pardanaud L, Luton D, Prigent M, Bourcheix LM, Catala M, Dieterlen-Lievre F. Two distinct endothelial lineages in ontogeny, one of them related to hemopoiesis. Development. 1996; 122:1363-1371. [PubMed: 8625825]

Pardanaud L, Yassine F, Dieterlen-Lievre F. Relationship between vasculogenesis, angiogenesis and haemopoiesis during avian ontogeny. Development. 1989

Patten BM, Kramer TC. The initiation of contraction in the embryonic chick heart. American Journal of Anatomy. 1933; 53:349-375.

Pauto MP. Determining the role of the mesoderm in the specific differentiation of the leg in birds. Arch Anat Microsc Morphol Exp. 1968; 57:311-321. [PubMed: 4978281]

Peault BM, Thiery JP, Le Douarin NM. Surface marker for hemopoietic and endothelial cell lineages in quail that is defined by a monoclonal antibody. Proceedings of the National Academy of Sciences. 1983; 80:2976-2980.

Petitte JN, Clark ME, Liu G, Verrinder Gibbins AM, Etches RJ. Production of somatic and germline chimeras in the chicken by transfer of early blastodermal cells. Development. 1990; 108:185-189. [PubMed: 2351062]

Pudliszewski M, Pardanaud L. Vasculogenesis and angiogenesis in the mouse embryo studied using quail/mouse chimeras. Int. J. Dev. Biol. 2005

Rawles ME. JSTOR: Physiological Zoology. Physiological Zoology. Jan.1943 16(1):22-43. 1943.

Reese DE, Hall CE, Mikawa T. Negative Regulation of Midline Vascular Development by the Notochord. Developmental Cell. 2004

Ribatti D, Vacca A, Roncali L, Dammacco F. The chick embryo chorioallantoic membrane as a model for in vivo research on angiogenesis. Int. J. Dev. Biol. 1996; 40:1189-1197. [PubMed: 9032025]

Salter DW, Smith EJ, Hughes SH, Wright SE, Crittenden LB. Transgenic chickens: insertion of retroviral genes into the chicken germ line. Virology. 1987; 157:236-240. [PubMed: 3029962]

Sanders TA, Llagostera E, Barna M. Specialized filopodia direct long-range transport of SHH during vertebrate tissue patterning. Nature. 2013; 497:628-632. [PubMed: 23624372]

Sato Y, Kasai T, Nakagawa S, Tanabe K. Stable integration and conditional expression of electroporated transgenes in chicken embryos. Developmental .... 2007

Schneider RA, Helms JA. The cellular and molecular origins of beak morphology. Science. 2003; 299:565-568. [PubMed: 12543976]

Scott BB, Lois C. Generation of tissue-specific transgenic birds with lentiviral vectors. Proceedings of the National Academy of Sciences. 2005; 102:16443-16447. 
Serbedzija GN, McMahon AP. Analysis of Neural Crest Cell Migration in Splotch Mice Using a Neural Crest-Specific LacZ Reporter. Developmental Biology. 1997

Stalsberg H, DeHaan RL. The precardiac areas and formation of the tubular heart in the chick embryo. Developmental Biology. 1969

Swartz M, Eberhart J, Mastick GS, Krull CE. Sparking New Frontiers: Using in Vivo Electroporation for Genetic Manipulations. Developmental Biology. 2001

Tickle C, Lee J, Eichele G. A quantitative analysis of the effect of alltrans-retinoic acid on the pattern of chick wing development. Developmental Biology. 1985

Tucker AS, Lumsden A. Neural crest cells provide species-specific patterning information in the developing branchial skeleton. Evol Dev. 2004; 6:32-40. [PubMed: 15108816]

van de Lavoir MC, Mather-Love C, Leighton P. High-grade transgenic somatic chimeras from chicken embryonic stem cells. Mechanisms of .... 2006

Wallis JW, Aerts J, Groenen MAM, Crooijmans RPMA, Layman D, Graves TA, Scheer DE, Kremitzki C, Fedele MJ, Mudd NK, et al. A physical map of the chicken genome. Nature. 2004; 432:761-764. [PubMed: 15592415]

Watanabe M, Choudhry A, Berlan M, Singal A, Siwik E, Mohr S, Fisher SA. Developmental remodeling and shortening of the cardiac outflow tract involves myocyte programmed cell death. .... 1998

Zhu L, van de Lavoir M-C, Albanese J, Beenhouwer DO, Cardarelli PM, Cuison S, Deng DF, Deshpande S, Diamond JH, Green L, et al. Production of human monoclonal antibody in eggs of chimeric chickens. Nature Biotechnology. 2005; 23:1159-1169. 

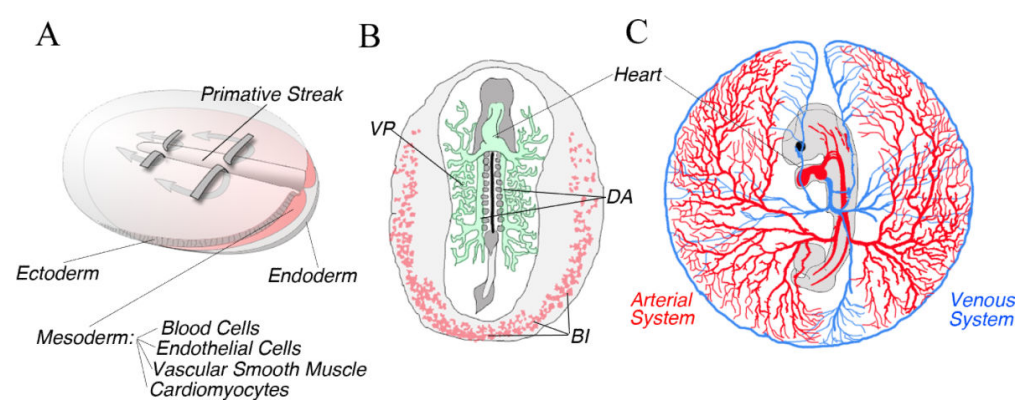

Figure 1.

Early cardiovascular development in avians. A) Diagram of avian gastrulation. Epiblasts cells ingress through the primitive streak generating the three germ layers (ectoderm, mesoderm, and endoderm. cardiovascular lineages including blood, endothelium, smooth muscle and cardiac muscle are derived from the mesoderm. B) Shortly after gastrulation vasculogenesis initiates. The first major blood vessels, the paired dorsal aorta (DA) form adjacent to the embryonic midline. These vessels are flanked by a dense vascular plexus (VP). Coincident with these events the extra-embryonic blood islands (BI), which give rise to primitive blood and endothelium form along the posterior periphery of the embryo. C) As the embryo increases in size the extra embryonic vascular extends out from the embryonic disk forming and arterial and venous system for gas and waste exchange. 

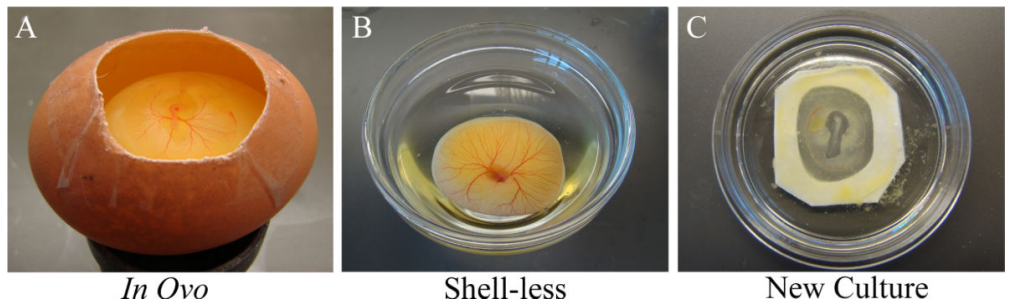

Figure 2.

Techniques for embryonic manipulation. A) A windowed egg prepared for in ovo manipulation. B) Embryo maintained in shell-less culture. C) Modified New culture with embryo developing on an albumen-agar substrate. 

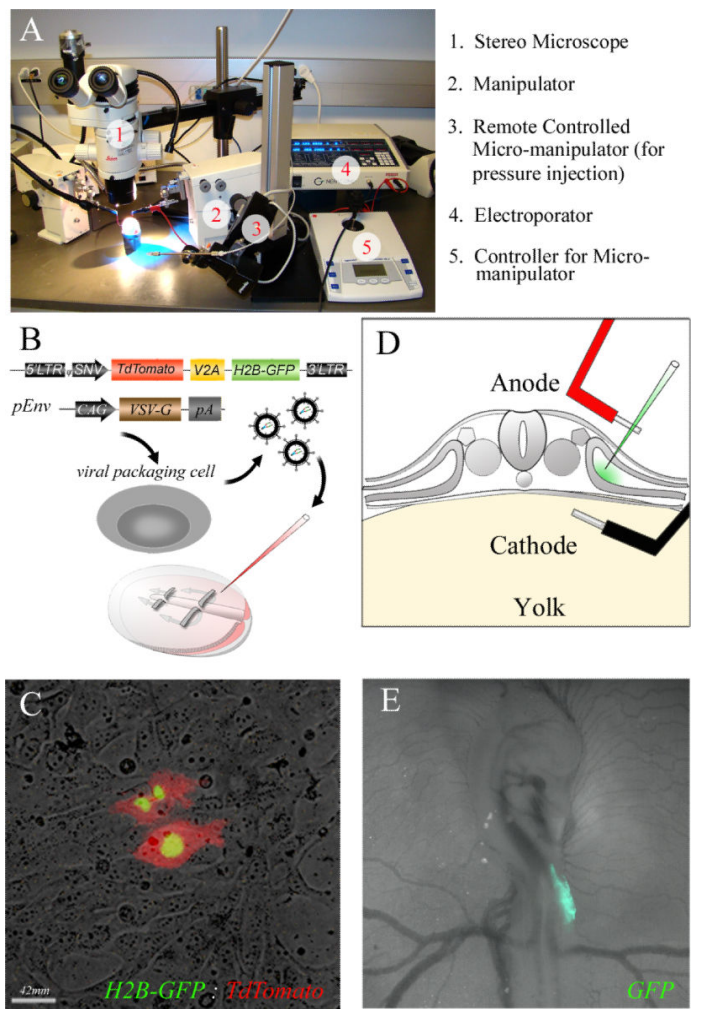

Figure 3.

Avian somatic transgenesis. A) Typical work station for viral micro-injection and plasmid electroporation. B) Construction and injection of a replication-incompetent retrovirus. Viral plasmid lacking packaging genes is transfected into a packaging cell line. These cells produces viral particles which are collected and injected into an embryo were they infect and integrate into the host cell genome. C) Example of cells infected with a viral vector containing H2b-GFP and a membrane bound Tdtomato. D) Diagram of in ovo electroporation into the avian limb field. The DNA plasmid is injected into the embryonic celoem and current is applied across the embryo. The plasmid is pulled into the cytosol of the host embryo. E) GFP expression in the forelimb of a chick embryo 24 hrs after electroporation. 